\title{
Performance analysis and research of the balance model foam concentrate mix equipment
}

\author{
Liu Zhu ${ }^{1}$,Hong-wu Chen ${ }^{1}$, Hai-peng Zhang ${ }^{1}$,Shi-ai Ren\& Shan-shan $\mathrm{Wu}^{1}$ \\ ${ }^{1}$ Department of College of Engineering Science and Technology, Shanghai Ocean University, \\ Shanghai, 201306, China
}

Keyword: The balance model foam concentrate mix equipment; AMESIM; Model; foam mixing ratio;

\begin{abstract}
In this paper, the static and dynamic performance of balance model foam concentrate mix equipment and establish mathematic model of this machine, and analyze byusing AMESIM simulation software.According to the national standard foam extinguishing system and parts general technical conditions to relevant test of the device, through data analysis and processing results compared with the results of simulation analysis, it conform to the established simulation model and the actual situation.

Foam extinguishing system is more rapid development both at home and abroad this year a fire control system, is researched, refinery, oil chemical plant, oil tank area, power plant, garage, hangar, etc.The main fire extinguishing system. Foam extinguishing system is mainly composed of water, water pump, foam liquid supply, inductor, line, bubble device, etc. Foam extinguishing system according to different foaming multiples of foam extinguishing agent can be divided into low expansion foam extinguishing system, the expansion foam extinguishing system and three types of high expansion foam extinguishing system.

Foam extinguishing system development plan is based on the model of system engineering, through the model to support system requirements definition, design,analysis, test and verify, starting from the concept design phase has been throughout the entire development process, namely, the development of modern products has turned to model-driven development process. Based on modular modeling idea [4] to hybrid foam extinguishing device, on the basis of the dynamic model of component defines each component has a certain relationship between input and output module, using the AMESIM model library, compile the simulation module of the items constituting the system, as a case study of balance type foam inductor component module development process is given. And by establishing the model of each component, design to establish a hybrid model of foam extinguishing system, studies the performance of the system.
\end{abstract}

\section{Balance type bubble proportion static and dynamic characteristics}

Balance type foam proportional mixing device by pump, relief valve, balance type foam of inductor, the mixing ratio is mainly determined by the balance type foam inductor. Balance type foam proportional mixer mainly consists of two dynamic pressure regulating function, will be a mixture of foam concentrate and sufficient fire water. When the pressure of the fire water changes, balance type bubble inductor using diaphragm pressure compensation adjustment, makes the pressure of foam concentrate of export and import of the pressure difference between the foam concentrate keeps constant, to get higher accuracy of foam and water mixture.

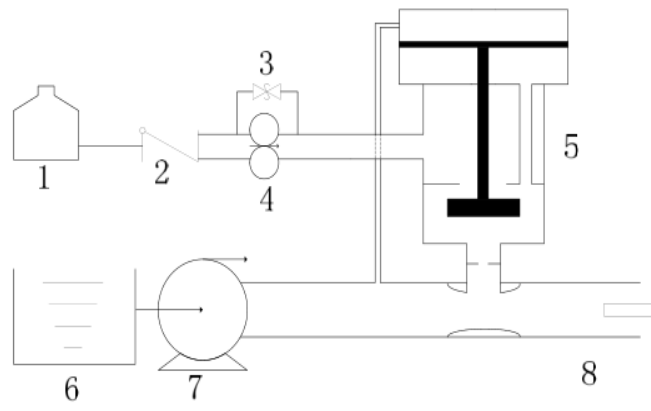

Fig.1:Balance type bubble proportion schematic diagram

Based on the principle of balance type foam inductor using true software AMSIM modeling was 
carried out on the balance type foam proportion, according to the international standard products parameters to set the parameters of the model and simulation, according to the simulation results and comparison of experimental data to verify the correctness of the model, for the balance type bubble inductor structure parameters and control parameters optimization design provides the basis.

\section{The working principle of balanced bubble proportion}

Balance type bubble inductor structure as shown in figure, the device to the master valve, diaphragm, the mixer of three parts. When the pressure of the fire water In the ideal state, namely fire water in pipe flow process without loss of pressure, the diaphragm in the stationary state. When fire water flow in the management process due to factors such as friction pressure loss caused the balance type bubble dynamic, inlet pressure of proportional balance type bubble inductor by regulating the diaphragm on the inferior vena and cavity pressure change to drive the movement of the main valve core, adjust the change of foam concentrate outlet pressure.

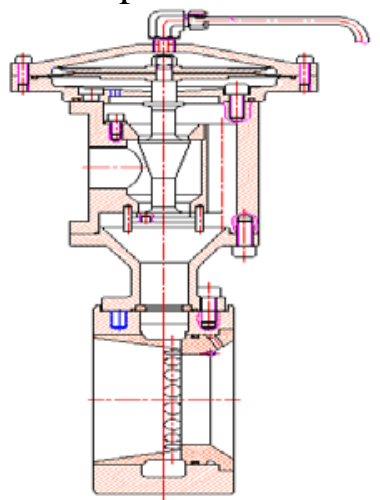

Fig.2:Balance type bubble inductor structure

Balanced dynamic characteristic of the bubble proportion refers to the balance type foam proportional mixer output pressure in response to disturbance quantity (fire water throughput). Balance type bubble proportion dynamic performance is good or bad depends on the pressure regulating valve inlet pressure error and transition process of regulating the smaller error, the shorter the transition time, the better the dynamic characteristics of valve. In order to analyze the dynamic behavior of balance type foam proportion, pressure regulating valve movement differential equation (mathematics) model, and the computer simulation using AMESIM software.

When balance type foam inductor is working, the stress of the valve core is balanced. A1 is the area of the diaphragm chamber, A2 is the area of the diaphragm inferior vena, as the gravity of the valve core, for diaphragm spring, Fs for steady state power on the valve core, for friction, import pressure P1 for fire water, give priority to the pressure at the top of the valve core p2, P3 is balanced type foam proportion export pressure, the main valve core on the force balance equation as follows:

$$
P_{1} A_{1}+M \mathrm{~g}+F_{\mathrm{g}}+F_{f}+F_{\mathrm{g}}=P_{2} A_{2}+P_{3} A_{3}
$$

Set a spring stiffness of main valve core, $\mathrm{x}$ is the amount of open valve core of the spring diaphragm compressed volume, then open valve core quantity too force can be represented as:

$$
F=K_{S}\left(X-X_{R}\right)
$$

Will type into the valve on the mechanical equations, and ignore the friction of the valve core, the weight and the transient fluid power, too:

$P_{1} A=K_{S}\left(X-X_{R}\right)+P_{2} A$

The deformation of diaphragm, relative to the amount of pre-compression diaphragm is negligible, to simplify the formula

$$
P_{1}-P_{2}=\frac{K X_{1}}{A}
$$

By formula can be seen that the main valve core pressure at the ends of the up and down by the diaphragm stiffness, amount of compression, and the cross section area of main valve core structure parameters, such as, once the design is completed, the pressure difference between the upper and lower ends of the main valve core as a fixed value. At the ends of the valve outlet flow and flow through the valve and flow rate are equal, the flow formula shows that the foam concentrate outlet pressure and fire water inlet pressure of multiple relationship, foam concentrate outlet pressure and 
fire water inlet pressure difference as a constant value, realize the constant pressure difference control, ensure the balance type foam proportional mixer mixing ratio accuracy.

\section{Balance type bubble proportion AMESIM modeling simulation and the result analysis}

Balance type foam proportional mixer mainly consists of two parts, the diaphragm, valve core, the main valve adopts the structure of the cone valve type. Balance type foam inductor Design in this paper, Hydraulic components in the AMESIM libraries without the same element structure, thus using the Hydraulic Compinent Design library of basic components to build balanced bubble inductor structure, as shown in the figure.

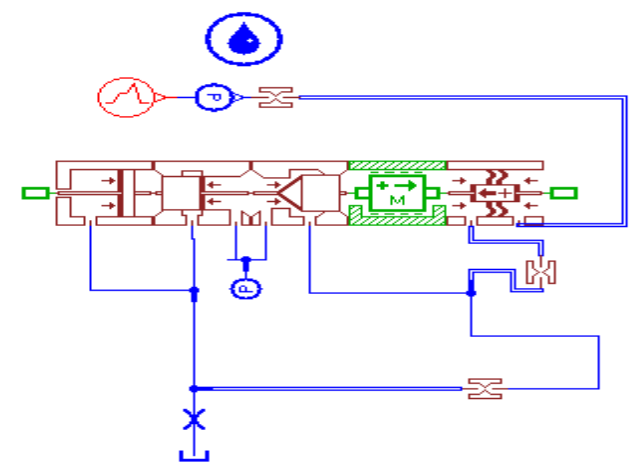

Fig.3:Balance type foam proportion simulation model

Build good balance type foam inductor model, set up sub-model, need in AMESIM parameters setting; The main valve core diameter of $18 \mathrm{~mm}$; Cylinder cavity length 64; Diversion hole diameter is $23 \mathrm{~mm}$, the main valve core and the diaphragm between damping hole diameter is $6 \mathrm{~mm}$; The maximum number of opening valve is $22 \mathrm{~mm}$; The simulation time is $20 \mathrm{~s}$, communication interval is $0.001 \mathrm{~s}$.

\section{Interpretation of result}

To balance type foam proportion import a variable step signal fire water, $0 \mathrm{~s} \sim 5 \mathrm{~s} 8$ bar signal, plus a $5 \sim 10$ seconds to add a 9 bar signal, $10 \sim 15$ seconds with a signal of 10 bar. Change order step load balance type foam proportional mixer outlet pressure as shown. Variable step load balance type foam fire water inlet pressure of proportional superposition signal as shown, balance type foam fire water inlet pressure of inductor and the concentrate outlet pressure difference as shown. The figure shows: balance type foam proportional mixer foam concentrate outlet pressure and fire water inlet pressure for the fixed value, the difference between the balance type foam proportional mixer foam concentrate outlet pressure varies with fire water pressure, the response speed is faster, realized the differential pressure constant value control.

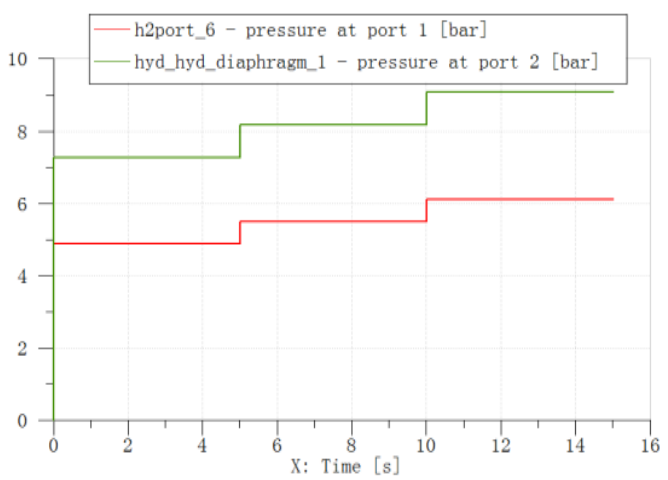

Fig.4:Fire water inlet pressure and foam concentrate outlet pressure curve

Simulation experiments by above knowable, regardless of the balance type foam fire water inlet pressure of inductor, as long as the balance type bubble proportion within the scope of regulation, the fire of the mixer can always ensure water pressure and the pressure of the foam concentrate the difference as a fixed value. By mixing ratio formula, in this case, can guarantee the mixing ratio of a certain value, thus ensuring the precision of mixing ratio of proportional balance type bubble. 


\section{The test and analysis}

According to the national standard GB20031-2005 "the foam extinguishingsystem and parts general technical conditions" test procedure for testing [7], because the test is mainly to verify the correctness of the simulation model is suggested, so the test is mainly to detect fire the differential pressure and the mixing ratio of water and foam concentrate. Test installation method as shown.

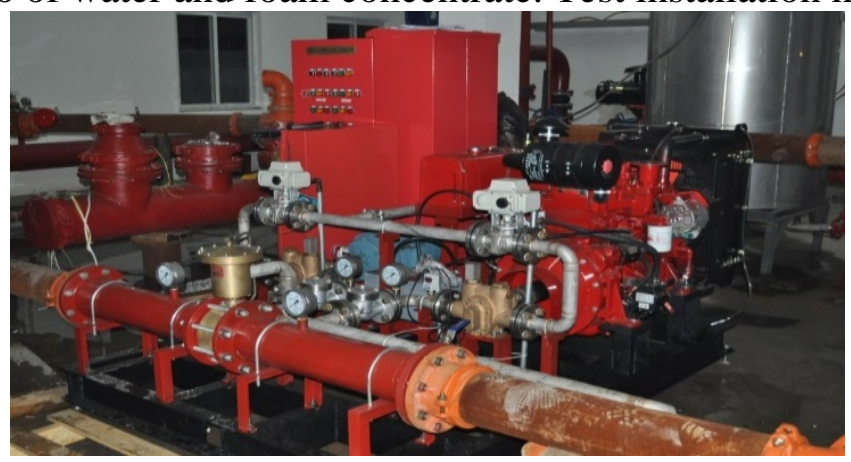

\section{The pressure loss}

Fig.5:Field test

Under water condition experiment, open the diesel water pump, open the butterfly valve 3, diesel engine inlet valve, butterfly valve, butterfly valve $6,5,8$, gate valve, butterfly valve, gate valve 5 and 92 gate 3, close the gate valve, butterfly valve 1, butterfly valve, butterfly valve, 2 and 4, butterfly valve, gate valve, 4 .

By adjusting the by-pass butterfly valve (6) and the mixture of the drain outlet valve gate valves (5) traffic to meet the specified pressure and flow value. Balanced proportion mixing device within the normal operating pressure range $0.60 .8 \mathrm{MPa}$, flow from the minimum value in turn increased to a maximum of $30 \mathrm{l} / \mathrm{s}-100 \mathrm{l} / \mathrm{s}$, take five sites. Balanced proportion mixing device of the inlet pressure and flow rate to achieve specified value, stable after read proportion import pressure gauge and outlet pressure value.

The system pressure loss test data in table 1

\begin{tabular}{|l|l|l|l|l|l|}
\hline \multirow{2}{*}{ flow gauge1 } & $108 \mathrm{~m}^{3} / \mathrm{h}$ & $162 \mathrm{~m}^{3} / \mathrm{h}$ & $216 \mathrm{~m}^{3} / \mathrm{h}$ & $270 \mathrm{~m}^{3} / \mathrm{h}$ & $324 \mathrm{~m}^{3} / \mathrm{h}$ \\
\cline { 2 - 6 } & $30 \mathrm{l} / \mathrm{s}$ & $45 \mathrm{l} / \mathrm{s}$ & $60 \mathrm{l} / \mathrm{s}$ & $75 \mathrm{l} / \mathrm{s}$ & $90 \mathrm{l} / \mathrm{s}$ \\
\hline flow gauge3 & 0.65 & 0.65 & 0.65 & 0.65 & 0.65 \\
\hline flow gauge4 & 0.64 & 0.638 & 0.634 & 0.635 & 0.627 \\
\hline pressure loss & 0.01 & 0.012 & 0.016 & 0.015 & 0.023 \\
\hline
\end{tabular}

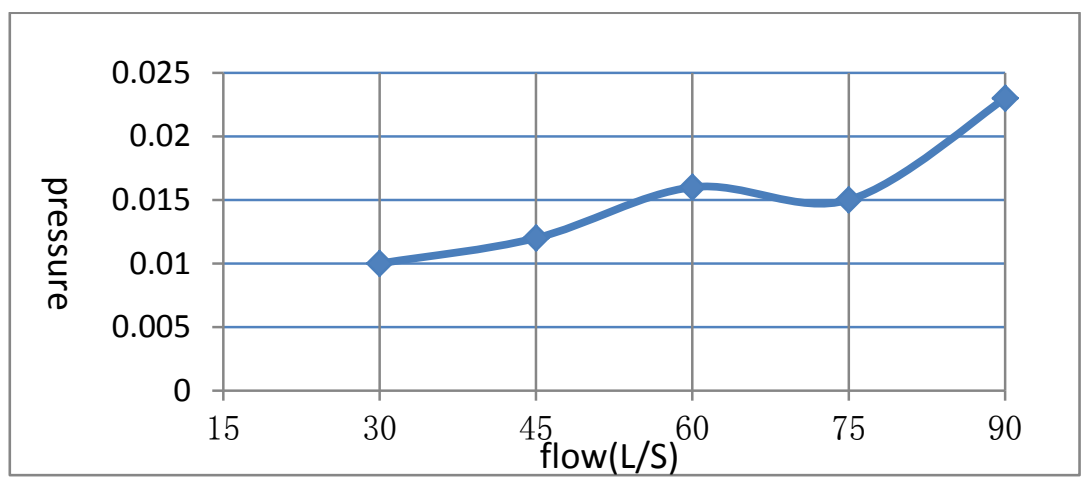

Fig.6: Loss of pressure curve

4.1, the mixing ratio test

4.1.1, foam test

1. The foam concentrate to the storage tank with foam concentrate $3 \%$.

2. According to the above will be balanced proportion mixing device installation.

3. In a standard mixing ratio value as the center, in a test tube, such as measuring cup with five kinds of mixing ratio of the mixture sample standard, four kinds of debugging experiment datum, the mixture of water and water quality are the same, $2 \%, 3 \%, 4 \%$ and $5 \%$ respectively, after their respective mix, use guide all $2 \%, 3 \%, 4 \%$ and $3 \%$ of electrical conductivity measurement and record. (measuring cups and conductivity test bar should be clean, without sundry, etc.) [8] note field take a 
bucket of water used for washing, prepare some clean paper, cotton cloth, disposable cups, four plastic buckets, etc. Manual debugging of 4 kinds of mixing ratio measuring cup:
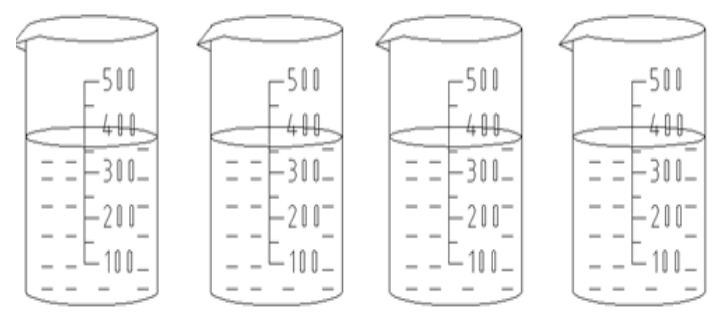

Mixture of $2 \%$ mixture of $3 \%$ mixture of $4 \%$ mixture of $2 \%$

Using electrical conductivity instrument measuring conductance value: standard mixture conductivity value)

Table 2Standard mixture conductivity value

\begin{tabular}{|l|l|l|l|l|}
\hline mixing ratio & $2 \%$ & $3 \%$ & $4 \%$ & $5 \%$ \\
\hline Conductance value & 2.79 & 3.65 & 4.55 & 5.36 \\
\hline temperature & 20.6 & 20.7 & 20.5 & 20.8 \\
\hline
\end{tabular}

Open the diesel pump, open the butterfly valve 3, diesel engine inlet valve, butterfly valve, butterfly valve $6,5,7$, gate valve, butterfly valve, gate valve 5 and 92 gate 3 , close the gate valve, butterfly valve 1 , butterfly valve, butterfly valve 4, 8, 2 gate 4 . 5], by adjusting the by-pass butterfly valve (6) and the mixture of the drain outlet valve gate valves (5) the flow to meet the specified pressure and flow value. Within the normal operating pressure range $0.60 .8 \mathrm{MPa}$, flow from theminimum value in turn increased to a maximum of $30 \mathrm{l} / \mathrm{s}-100 \mathrm{l} / \mathrm{s}$, take five sites, 1 meter, respectively. [6], according to five different flow point, separately in plastic drum, fills in turn in place. In the plastic, foam mixture in five disposable cups, respectively according to five different survey points corresponding to put. Once, the electrode conductivity meter stick to clean clean, one by one test every cup of the conductance of the mixture, and record.

Table 3Different fire water pressure and the mixing ratio of foam concentrate

\begin{tabular}{|c|c|c|c|c|c|}
\hline Flow value & $\begin{array}{c}108 \mathrm{~m}^{3} \\
/ \mathrm{h}\end{array}$ & $\begin{array}{c}162 \mathrm{~m}^{3} \\
/ \mathrm{h}\end{array}$ & $\begin{array}{c}216 \mathrm{~m}^{3} \\
/ \mathrm{h}\end{array}$ & $\begin{array}{c}270 \mathrm{~m}^{3} \\
/ \mathrm{h}\end{array}$ & $\begin{array}{c}324 \mathrm{~m}^{3} \\
/ \mathrm{h}\end{array}$ \\
\cline { 2 - 6 } & $301 / \mathrm{s}$ & $451 / \mathrm{s}$ & $601 / \mathrm{s}$ & $751 / \mathrm{s}$ & $901 / \mathrm{s}$ \\
\hline Plastic drum & 1 & 2 & 3 & 4 & 5 \\
\hline Disposable cups & 1 & 2 & 3 & 4 & 5 \\
\hline $\begin{array}{c}\text { Testing } \\
\text { conductance value }\end{array}$ & 4.52 & 4.33 & 4.20 & 4.0 & 3.66 \\
\hline
\end{tabular}

8, according to the test of four kinds of conductance values and compare four kinds of manual debugging conductance value, can calculate the foam mixture mixing ratio. Mixing ratio and flow chart.

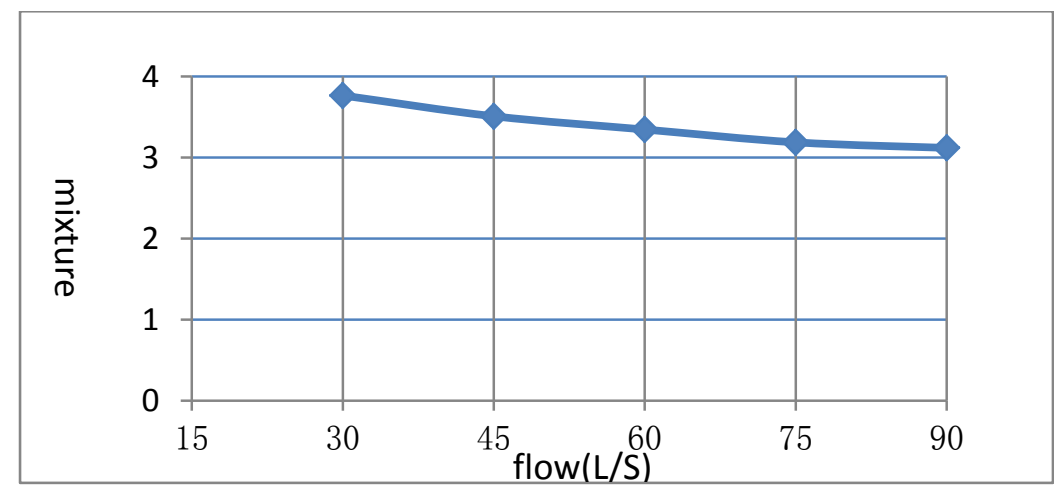

Fig.6:Main system than graph: (the water in the mixture)

According to the test, the fire water and foam concentrate after balance type foam proportion fully mixing, when the pressure of the fire water fluctuate within a certain range, through the balance type foam proportion own adjustment can guarantee the foam concentrate stress and the pressure difference between the fire water imported basic remains the same, the mixing ratio conversion formula and ensured the mixing ratio unchanged. 


\section{Conclusion:}

Based on AMESIM balance type foam inductor model is established, according to foreign products to set up the structure parameters and control parameters of the simulation balance type bubble inductor, the various performance parameters for our country independent design and to balance type foam proportionstructure parameters and control parameters optimization design provides the basis. Through AMESIM simulation experiment, and comparing the actual data, the actual situation to download under the condition of different fire water pressure adjustment, foam concentrate by balance is bubble proportionand fire water mixing ratio remain relatively stable, and the simulation results that the balance type foam fire water inlet pressure of inductor is always the result of the pressure difference between the foam concentrate and constant is consistent, so know balance type bubble working principle is similar to or worse of proportional pressure reducing valve.

\section{Acknowledgements}

Corresponding author: Hong-wu Chen. Department of College of Engineering Science and Technology,Shanghai Ocean University, Shanghai, 201306, China.The research work was supported by National Natural ScienceFoundation of China under Grant No.51075258and Shanghai alliance project LM201140.

\section{References:}

[1] GB20031-2005 General technical requirements foam extinguishing systems and components.

[2]Zhi Jun-Yang, pumping balance pressure type foam proportional mixing device design [D]. Shanghai: Shanghai jiaotong university, 2003.

[3] Tension. The modeling and simulation of AMESIM based on constant pressure reducing valve. Mechanical engineering and automation, 2013 (180) : 0058-03.

[4]Zhongdong-Zhang. Compressed air foam system design and simulation. Shandong, shandong university, 2012.

[5] Pahl G, Beitz W. Engineering Design-A Systematic approach [M].2nd ed.London: Springer Verlag, 2000

[6] Zai Jun-Wang, Stationary deck foam extinguishing system security check discussion[J].CHINA WATER TRANSPORT, 2007(11): 24-25.

[7] GB50151-2010 Foam extinguishing system design specifications

[8] Xiu-Li Hu. Electrical conductivity measurement principle [J]. Science and technology BBS. 2010:41 and 42 